\title{
Binge Eating and Quality of Life: Analysis of Gender and Ethnicity
}

\author{
${ }^{1}$ DYAH KUSBIANTARI, ${ }^{2}$ EFI FITRIANA, \\ ${ }^{3}$ ZAHROTUR RUSYDA HINDUAN, ${ }^{4}$ WILIS SRISAYEKTI
}

\footnotetext{
${ }^{1}$ Ivet University, Jl. Pawiyatan Luhur IV / 17 Bendan Dhuwur Semarang, Central Of Java, Indonesia, ${ }_{1,2,3,4}$ Padjajaran University, Jl. Raya Bandung Sumedang KM.21, West Java, Indonesia Correspondence author: dyahkusbiantari@gmail.com
}

\begin{abstract}
Changing in eating activities as social interaction and for expressing emotions may affect the desire to eat large amounts of food, and when it goes out of control, the eater then regrets it; this is called binge eating. Binge eating causes a decrease in the quality of life (QOL) or well-being of a person. QOL is often considered a standard of living by most people and is considered a cross-cultural problem. This study aims to examine the relationship between binge eating and quality of life. This correlation is also compared across to distinguish gender and ethnicity. The participants were 553 undergraduate students in Semarang, Indonesia. The data were analyzed using the correlational method and t-tests. The findings showed that binge eating has a negative correlation with quality of life. This study also found that there was no gender difference in binge eating and quality of life. Although there was no difference in binge eating and quality of life among various ethnicities, the majority of them experienced severe binge eating.
\end{abstract}

Keywords: quality of life, binge eating, ethnicity

\section{Introduction}

Eating behavior in the millennial era changed. Originally, eating was one of the ways of life's survival, but now it changes into a lifestyle. This changing may be influenced by social media, billboards, and entertainment programs that expose various appetizing dishes. Eating activities can be a symbol of social interaction, economic power through food availability, and the choices of foods served. Eating can also become a channel for expressing emotions, for example, anger, disappointment, happiness, and other emotions, which may affect the desire to eat large amounts of food. Sometimes this desire can be out of control, but the eater regrets it after. Eating conditions like this are called binge eating.

Binge eating is a temporary maladaptive strategy to avoid or eliminate the frequency or intensity of negative memory, feelings, and evaluation from feeling inferior, criticized, or rejected by others (Duarte \& Pinto-Gouveia, 2017).
Binge eating has the characteristics of eating in large quantities without any compensatory behavior such as taking laxatives or regurgitating food that has been swallowed (American Psychiatric Association, 2013). Binge eating occurs mostly in both clinical and non-clinical populations (Duarte, Pinto-Gouveia and Ferreira, 2015; Escrivámartínez, Galiana, and Rodríguez-Arias, 2019; Kessler et al., 2013; Hudson et al., 2007). Binge eating can occur in both men and women with peak onset after puberty, on average at the age of 14 years and 19-24 years (Gan, Mohamad, and Law, 2018; Stice, Presnell, and Spangler, 2002).

Binge eating harms daily life, among others, the individual withdraws from social life due to the shame of hanging out with other people resulting in loss of contact with those closest to him; individuals experiencing anxiety and depression (Grilo, White, Gueorguieva, Barnes, \& Masheb, 2013). Binge eating causes a decrease in the quality of life or well-being of a person which

Received: 2020-04-25, Revised: 2020-09-16, Accepted: 2020-12-29

Print ISSN: 0215-8175; Online ISSN: 2303-2499. DOI: https://doi.org/10.29313/mimbar.v36i2.5979

Accredited Sinta 2 based on the decree No.10/E/KPT/2019 until 2024. Indexed by DOAJ, Sinta, Garuda, Crossreff, Dimensions 
affects a person's physical, psychological, social, economic conditions such as being unemployed, increasing the risk of death and even suicide (Fichter, Quadflieg, \& Hedlund, 2008; Rieger et al., 2005; Zwaan et al., 2002). WHO defines well-being as individuals' perceptions of their position in their lives in the cultural context, the value system in which they live, related to their goals, expectations, standards, and concerns. All of these concepts in various ways affect physical, psychological health, self-confidence, social relationships, and their interactions with the environment (Post, 2014; Rieger et al., 2005; Skevington, Lotfy, \& Connell, 2004; Zwaan et al., 2002 ).

Kushner \& Foster (2000) said that in terms of construct, welfare or quality of life (QOL) refers to how a person feels life satisfaction. QOL is often considered a standard of living by most people and is considered a cross-cultural problem. Various indicators are build to set the standard of living as a goal to measure welfare. Therefore, welfare is measured by a series of 'objective' parameters, even though welfare is a subjective perception of various important aspects of a person's life that may not be the same as what constitutes a common consensus as an indicator of living standards (Suzanne M Skevington, 2002; SM Skevington, Lotfy, \& Connell, 2004)

Suzanne M Skevington (2002) states that welfare is a social construction because it comes from its meaning, which is obtained by someone from an important aspect of their lives. A person's welfare is very subjective. Thus, the welfare of a person depends on how the person perceives it.

In Javanese culture, there is an assumption that the portion of food that has been served must be finished, assuming it is not polite or even getting a threat that the pet chickens will die if the food is not finished (Samiaji, 2019). Therefore, habituation occurs to eat all the food presented even though a person has already full. There are various eating behaviors, in which a person eats a lot of food but then regret having eaten too much or eating in absence of hunger or keep eating even though it is full.

This study aims to look at the relationship between binge eating with quality of life, the implications of binge eating in ethnic Javanese and non-Javanese in Semarang who experience binge eating, and sex comparison to BES scores as reported by previous studies (Gan et al., 2018; Rieger et al., 2005; Zwaan et al., 2002). This study has a novelty i.e there are no previous studies that looked at the implications of ethnic Javanese and the relationship between welfare with binge eating and its severity.

\section{Research Methodology}

This research was conducted on students in Semarang using a descriptive and quantitative approach. The descriptive approach is presented in the form of a central tendency that can be presented in the form of averages, medians and quantitative approaches done through data collection then presented in the form of numbers, average scores of several tasks from different groups, percentage of people who do or don't do something, graphs, data tables and so on (Goodwin \& Goodwin, 2017).

Participants in this study were 553 bachelor students from 3 private universities in Semarang City, aged 17-25 years. Participants were asked to fill out their curriculum vitae and voluntary statements before filling out a measuring instrument in the form of a questionnaire. Data on ethnicity and gender were obtained through curriculum vitae filled out by participants.

The type of data in this study is primary data obtained through measuring tools Binge Eating Scale (BES), WHOQOLBREF (World Health Organization Quality of Life Scale - Abbreviated form), and self data forms provided to participants. The BES and WHOQOL-BREF measuring instruments used are the Indonesian versions that have been translated through a process of forwarding and back translation according to guidelines issued by the ITC second edition (International Test Commission, 2016; Purba et al., 2018).

Binge Eating Scale (BES) (Gormally, Black, Daston, \& Rardin, 1982) in the form of a questionnaire measures cognitive/emotional symptoms and behavior related to binge eating. This instrument has a conceptual definition of measuring the severity of binge eating through the consumption of large amounts of food; at first, it was used for overweight eaters but now it is very widely used even in normal samples.

BES consists of 16 items, where each item consists of 3-4 statements that can be selected by one participant. The statement choices indicate the severity of each binge eating characteristic measured. The Binge Eating Scale has two structural factors, 
namely (1) Feeling (feeling guilty after eating too much) and cognition (thinking about bodyweight); (2) Behavioral Manifestation (8 grain) (Thurston, Hardin, Kamody, Herbozo, \& Kaufman, 2018).

The total overall score has a range of $0-46$. The greater the score shows a higher severity with the cut-off score: non/mild $\leq$ 17 , moderate $18-26$, serious/severe $\geq 27$. In previous studies, BES showed good validity and reliability (Duarte et al., 2015; Escrivá -martínez et al., 2019; Gan et al., 2018). The validity and reliability of BES in this study are well indicated by Cronbach's Alpha of 0.831 and all items have a significantly greater correlation than the coefficient r-table $=0.088$.

WHOQOL-BREF (World Health Organization Quality of Life Scale - Abbreviated form) (WHO, 2012) is a measuring tool developed by WHO to measure welfare from the participant's perspective and not to measure the success rate of a medical treatment method. WHOQOL-BREF measures four welfare domains: physical, psychological, social, and environmental, consisting of 26 items (Purba et al., 2018; WHO, 2012). The WHOQOL-BREF scoring results were changed by the transformation method $0-100$; the higher the value indicates the more prosperity (WHO, 1996). In previous studies, WHOQOLBREF showed high validity and reliability (Purba et al., 2018). In this study, the WHOQOL-BREF's relativity looks good, shown by Cronbach's Alpha of 0.923 and 25 items having a significantly greater correlation than the $r$-table coefficient $=0.088$. One item correlation is 0.085 , considering that this measuring instrument is a measure of adaptation and very little correlation under the $r$-table coefficient, then item number 3 is still considered in the analysis.

All analyzed statistical data used in this study were descriptive analysis and correlation between well-being and binge eating. Statistical analysis was performed using software of Excel 365 (Microsoft 365) and SPSS 21 (IBM Co.).

\section{Results and Discussion}

\section{Participant Descriptive Analysis}

Participants in this study consisted of 553 bachelor students, women ( $\mathrm{n}=373$; $67 \%)$, men $(n=180 ; 33 \%)$, with an average age of 19 years $(\min =17 ; \max =29$; Median = 19); based on the summary in the curriculum vitae, there were 4 people who fulfilled invalid data of birth, then corrected by confirmation by telephone. Marital status consisted of 551 unmarried people, 1 person refused to answer, 1 person married. Judging from the average Body Mass Index (BMI) obtained using the bodyweight formula divided by the square of the height, an average BMI of $22 \mathrm{~kg} / \mathrm{m} 2$ ( Min = 13.5; $\max$ = 39.45; $\mathrm{SD}=4,17$; Median = 20.77).

Participants in this study were all transitioning from adolescents to adulthood, also called emerging adults. At this age, the individual's need to be accepted by his environment and interact with his friends is important, conflict in social interaction greatly affects emotions and self-evaluation, and in their social activities, they influence each other including in eating activities. This age is also the peak age of onset of binge eating.

\section{Analysis of Binge Eating Prevalence and Severity}

Prevalence of binge eating from all samples $(n=553)$ : binge eating with non/ mild severity was $454(82.10 \%)$ consisting of 330 women $(59.67 \%)$ and 157 men (28.39 $\%)$; moderate was $53(9.58 \%)$ consisting of 38 women $(6.87 \%)$ and 20 men $(3.62 \%)$, severe was $8(1.45 \%)$ consisting of 5 women $(0,90 \%)$ and 3 men $(0.54 \%)$.

All of the samples, the prevalence of binge eating with the severity of non/mild had the highest number of 487 people divided into non-binge eating consisted of 47 people and mild of 440 people. Non binge and mild criteria were determined by the number of scores; participants who obtained zero score included in non-binge eating group, while participants with 1-17 score included in the mild group. Based on the BES total score, the minimum score is 0 and the maximum total score is 37 , the mean total score $=8.48$, the SD total score $=6.91$, according to research conducted by (Hudson et al., 2007; Kessler et al., 2013) which shows the prevalence of binge eating in both men and women.

The population in Semarang city showed only a few students have severity of non-binge eating that was $8.50 \%$, and the most severe category was $79.57 \%$, the mild group has not shown any binge eating disorder neither rule out the possibility that its severity increases; in order to prevent the increase of severity, this group needs attention to get prevention and treatment. The prevalence of binge eating with severity 
associated with ethnicity is shown in Table 1.

Table 1

Mapping Data on Java and Non-Java Ethnic

\begin{tabular}{lc}
\hline Ethnic & Total \\
\hline Java & \\
1. Jawa & 411
\end{tabular}

Non-Java

1. Aceh 1

2. Ambon

3. Badui

4. Bali

5. Batak

6. Batak Karo

7. Batak Jawa

8. Batak Sunda

9. Belanda, Suriname

10. Betawi

11. Bima

12. Bugis

13. Buton

14. Cina/ Tionghoa

15. Dayak

16. Ende lio

17. Flores

18. Jawa Bali

19. Jawa Cina

20. Kupang

21. Lampung

22. Lampung Betawi

23. Maluku

24. Minangkabau

25. Padang

26. Padang Palembang

27. Papua

28. Sasak

29. Sumatra Barat

30. Sunda

31. Sunda Betawi

32. Toraja

Total 553

Source: research results, 2020

\section{Analysis of Ethnic and Severity of Binge Eating}

Semarang City as one of the major cities in Indonesia has become a destination for various business and educational activities so that many residents are migrants from other cities and provinces. Based on the data obtained, it can be seen that there were 411 participants of Javanese ethnic (74\%) and 142 of non-Javanese (26\%). Non-Javanese ethnic groups consist of many other ethnic and mixed ethnic groups originating from a marriage between two ethnicities are presented in detail in Table 2.

\section{Table 2}

Data Mapping Ethnic And Binge Eating Severity

\begin{tabular}{lcccc}
\hline \multirow{2}{*}{ Ethnic } & \multicolumn{4}{c}{ Binge Eating Severity } \\
\cline { 2 - 5 } & Non & Mild & $\begin{array}{c}\text { Mode- } \\
\text { rate }\end{array}$ & Severe \\
\hline Jawa & 37 & 328 & 43 & 5
\end{tabular}

Non-Java

2. Ambon

3. Badui

4. Bali

5. Batak

6. Batak Karo

7. Batak Jawa

8. Batak Sunda

9. Suriname, Dutch

10. Betawi

11. Bima

12. Bugis

13. Buton

14. Cina/ Tionghoa

15. Dayak

16. Ende lio

17. Flores

18. Jawa Bali

19. Jawa Cina

20. Kupang

21. Lampung

22. Lampung Betawi

23. Maluku

24. Minangkabau

25. Padang

26. Padang Palembang

27. Papua

28. Sasak

29. Sumatra Barat

30. Sunda

31. Sunda Betawi

32. Toraja

Total

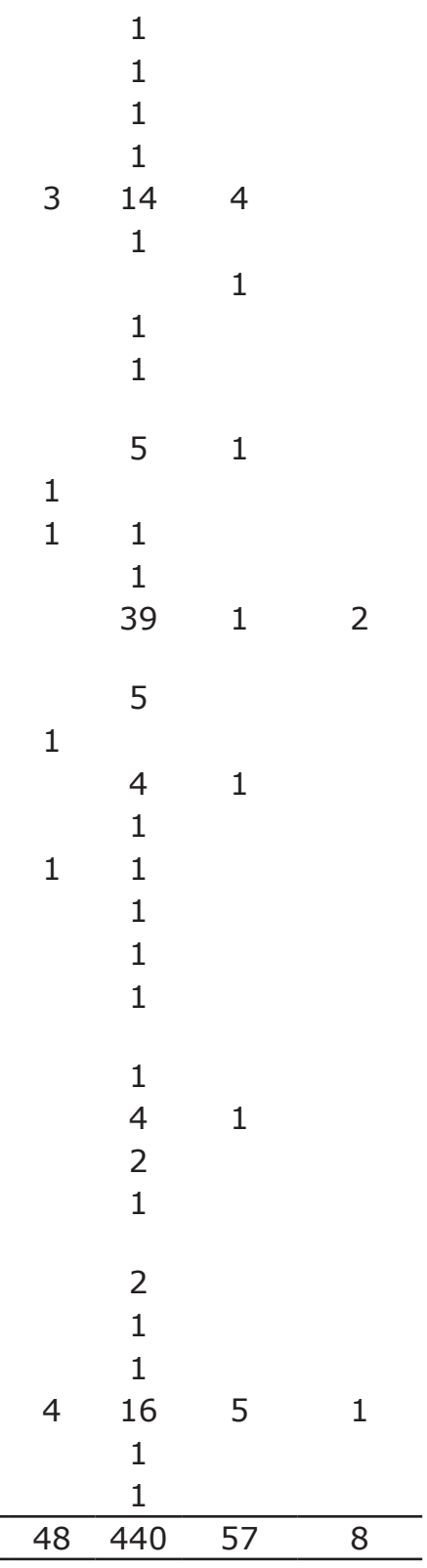

Source: research results, 2020

Javanese ethnicity shows the large numbers of severity that has become an eating disorder, namely moderate and severe, 
followed by ethnic of Sundanese, Chinese, and Batak.

The culture of eating outside is also increasingly preferred with more and more activities outside the home (Ariwibowo, 2015), especially for students who are mostly migrants from cities around Semarang. Many of these newcomers did not allow selfcooking, so the native students of Semarang City were also influenced to eat outside with their fellow students.

People's culinary lifestyle in Semarang is influenced by culinary tourism shows on television, films, and print media that encourages the desire to eat. Such culinary lifestyle is also supported by the increased economy and easy access to food, for example, food delivery through applications on mobile phones and the tendency to share photos of the food and the moment of eating with friends through social media. According to (Deluchi, Costa, Friedman, Gonçalves, \& Bizarro (2016), people with binge eating have a high tendency to show a strong approaching response to high-calorie food images.

According to (Chao, Grilo, \& Sinha, 2016), when someone is exposed to images of high-calorie foods displayed on social media, billboards, culinary tours, and social interactions that expose food, plus the ease of ordering food via food app/delivery makes him/her craving for the food. It is further encouraging the emergence of binge eating which is evident in Semarang City. The same thing also occurred in studies of populations in Spain that showed an association between a strong desire for certain foods and eating disorders (Cepeda-benito, Carmen, \& Moreno, 2003).

The types of food offered by culinary tourism in Semarang City are so diverse, from fatty and high-calorie traditional foods that are very closely related to the daily life of Javanese ethnic such as traditional coconut milk soup, curry, traditional soup, barren rice, and barley rice and others to current foods such as milk tea, pizza, boiled chicken nuggets, cakes, and a lot more which are very appetizing and contribute to excessive consumption of food. Therefore, the Javanese ethnicity shows a higher prevalence of binge eating and even more prevalence of binge eating that is included in the disorder category.

In Javanese culture, there is a threat that if you do not eat up all the food on your plate, you will have emotional problems, bad memories, and unpleasant experiences. According to Duarte \& Pinto-Gouveia (2016), memories from embarrassing experiences such as being bullied, dictated/receiving negative comments, or rejected because of weight, body shape, and physical appearance, are crucial factors that cause binge eating, just like the experience of sexual and emotional abuse during childhood and adolescence which become risk factors for binge eating symptoms later in life.

Non-Javanese ethnic in Semarang also shows the prevalence of binge eating which is included in the category of binge eating disorder even though the number is not as much as the Javanese ethnicity. Students of Non-Javanese ethnic are migrants in Semarang City who have a different eating culture compared to Javanese ethnicity.

\section{Sex Analysis of Binge Eating}

Analysis of the difference in BES scores by gender is needed to determine the role of gender in the occurrence of binge eating. Analysis of the difference in BES scores obtained by men $(M=7.756$; $S D=7.271)$ and women $(\mathrm{M}=8.836 ; \mathrm{SD}=0.348) ; \mathrm{df}=$ 330 , using statistical analysis independent sample $\mathrm{t}$-tests obtained $\mathrm{t}=-1,679<\mathrm{t}$ table $=1,153$. The results show there was no difference of BES scores in men and women. There was no significant difference between the treatment of binge eating in men and women. A study of populations in Spain conducted by Escrivá-martínez et al. (2019) showed there was no difference in response between men and women when comparing BES scores of men and women.

In the population of Semarang city, binge eating occured in both men and women. It happened due to changes in ethics and eating culture in Javanese ethnic where women and men have equal rights in fulfilling food needs and are free to eat outside the home, modernization of lifestyle and changes in family values for women that are allowed to consume food continuously and excessively, even if they are not hungry.

Keel et al. (2018) state people with binge eating experience satiety deficiency. A decrease in satiety is also related to the severity or frequency of binge eating. Individuals with binge eating disorders have an urge to keep eating, even though hunger is no longer felt or their stomachs are already full. 


\section{Analysis of Binge Eating and Welfare}

The relationship between welfare and binge eating, based on the results obtained from the analysis of the total BES score, without looking at the severity of binge eating, is associated with the total WHOQOLBREF score to see overall well-being. Factors of welfare measured are physical health, psychological health, social relations, and the environment as a total score; and the results of analysis on all above factors show a significant negative relationship with binge eating that can be seen in table 3 .

All the factors of welfare measured (physical health, psychological health, social relations, and the environment) show a significant negative relationship with binge eating. Thus, someone who is prosperous has less tendency to do binge eating. This has the meaning that someone who feels overall well being physically, psychologically healthy, having good social interaction, and living in good environment also feels satisfied would have small possibility to binge eating and vice versa; when a person has lower welfare, the greater the tendency to do binge eating. The results of the analysis showed that of all welfare factors, psychological wellbeing has the greatest negative relationship compared to other factors, indicating that the linkage of psychological well-being was greater to the existence of binge eating compared to physical health, social interaction and the environment. In other words, if a person experiences psychological problems, he is more likely to become binge eating than if he has physical problems, social interactions problems, or problems with environment.

Post (2014) says that well-being is a multidimensional construct based on one's self-assessment of physical, psychological, emotional, and social well-being. Post (2014) adds that the overall subjective satisfaction of life felt by a person makes that person feels his life on welfare. Thus, when a person feels in a state of prosperity as a whole, the tendency to become binge eating is also low as seen from the results of this study.

\section{Analysis of Quality of Life With Binge Eating Severity}

WHOQOL-BREF score analysis results of each factor, compared with BES scores, where non-binge eating grouping is a subject that has a total BES score of zero. This is done to find out the subjective well-being felt by the subject, which states that he has never experienced binge eating. Based on the scores obtained by the non-binge eating group, the scores had the highest average compared to

Table 3

Correlation between WHOQOL-BREF and BES Total Score

\begin{tabular}{llccccc}
\hline \multicolumn{1}{c}{ WHOQOL-BREF Factor } & $\mathrm{n}$ & Mean & $\mathrm{SD}$ & \multicolumn{1}{c}{$p$-value } \\
\hline 1 & Physical Health & 553 & 65.66 & 14.02 & -.269 & .109 \\
2 & Psychological Health & & 64.0 & 15.39 & -.295 & \\
3 & Social Relationship & & 63.2 & 17.50 & -.119 & \\
4 & Environment & & 64.90 & 15.41 & -.205 & \\
5 & Total Score & & 69.56 & 11.07 & $\mathbf{- . 2 9 5}$ \\
\hline
\end{tabular}

Note: Bold coefficient correlation is significant $(p<0.05)$ two-tail; WHOQOL-BRE : World Health Organization Quality of Life Scale-Abbreviated form; BES: Binge eating scale.

Source: research results, 2020

Table 4

WHOQOL-BREF Total Score and Binge Eating Severity

\begin{tabular}{lcccc}
\hline \multirow{2}{*}{ WHOQOL-BREF } & \multicolumn{3}{c}{ BES } \\
\cline { 2 - 5 } & Non & Mild & Moderate & Severe \\
\hline $\mathrm{n}$ & 47 & 438 & 58 & 8 \\
$\mathrm{M}$ & 69.56 & 11.07 & 64.91 & 41.67 \\
$\mathrm{SD}$ & 11.07 & 65,2 & 41.67 & -.543 \\
$\mathrm{r}$ & -- & -.178 & .017 & -.543 \\
$p$-value & -- & .094 & .259 & .707 \\
\hline
\end{tabular}

Note: Bold coefficient correlation is significant ( $<<0.05 ; 2$-tailed); $n$ : number of subject; M: mean; SD: standard deviation; WHOQOL-BREF: World Health Organization Quality of Life Scale-Abbreviated form; BES: Binge Eating Scale. 
the binge group with mild, moderate, and severe severity.

Kushner \& Foster (2000) state that subjective life satisfaction felt by someone shows how much welfare he feels. People with non-binge eating feel life satisfaction, especially on environmental factors. Post (2014) adds that life satisfaction felt by a person is conformity to his expectations and accomplishments over time. Therefore, people with high life satisfaction have a low tendency to become binge eating. Based on welfare factors, people with non-binge eating showed high rates of physical and psychological health factors, meaning that physical and psychological health factors were important factors in the non-binge eating group as shown in Table 5.

\section{Analysis of Quality of Life Factors with the Severity of Binge Eating}

The relationship between welfare and mild severity binge eating is seen to be significantly negative as shown in table 4 . This shows that people have mild binge eating when they feel their welfare is low; they tend to experience higher binge eating compared to moderate, severe, and non-binge eating.

Physical health and psychological health welfare factors have a significantly higher negative relationship than environmental welfare factors in people with mild binge eating as seen in table 6. Psychological health is the highest factor associated with mild severity binge eating. If a person with mild binge eating experiences a quality of life-related to problems of psychological health, physical health and a problem with the environment, then there is a tendency for binge eating to become higher.

Moderate severity binge eating does not show a significant relationship with all factors, in terms of the average WHOQOL-BREF score seen in social relationship factors that higher than other factors as seen in table 7. Thus, people with moderate binge eating are more satisfied with social relationships than other factors.

For people with severe binge eating, there is a significant negative correlation with physical health factors, while other factors do not show a significant negative relationship as seen in table 7. The lower the satisfaction of people with severe binge eating on physical health, the more they tend to binge eating.

\section{Conclusions}

Binge eating in Javanese ethnic occurs more than non-Javanese ethnic which also shows more prevalence of eating disorder than non-Javanese. There was no difference in binge eating among men and women in

Table 5

Characteristics of Quality of Life Factors and Non-Binge Eating

\begin{tabular}{llclc}
\hline & Quality of Life Factor & $\mathrm{n}$ & Mean & SD \\
\hline 1 & Physical Health & 47 & 69.90 & 12.74 \\
2 & Psychological Health & & 69.50 & 10.96 \\
3 & Social Relationship & & 66.13 & 20.52 \\
4 & Environment & & 72.14 & 15.82 \\
\hline
\end{tabular}

Note: Bold coefficient correlation is significant ( $p<0.05 ; 2$-tailed); $n$ : number of subject; SD: standard deviation.

Source: research results, 2020

Table 6

Coefficient Correlation of WHOQOL- BREF Subscales and Mild Binge Eating

\begin{tabular}{llccccc}
\hline & Quality of Life Factor & $\mathrm{n}$ & Mean & $\mathrm{SD}$ & $\mathrm{r}$ & $\mathrm{p}$ value \\
\hline 1 & Physical Health & 438 & 66.26 & 13.95 & -.172 & .094 \\
2 & Psychological Health & & 65.25 & 14.97 & -.178 & \\
3 & Social Relationship & & 63.96 & 16.84 & -.100 & \\
4 & Environment & & 64.91 & 15.01 & -.127 & \\
\hline
\end{tabular}

Note: Bold coefficient correlation is significant ( $\mathrm{p}<0.05 ; 2$-tailed); $\mathrm{n}$ : number of subject; SD: standard deviation; $r$ : coefficient correlation.

Source: research results, 2020 
Table 7

Coefficient Correlation of WHOQOL-BREF Subscale and Moderate and Severe Binge Eating

\begin{tabular}{|c|c|c|c|c|c|c|c|c|}
\hline \multirow{3}{*}{ WHOQOL-BREF } & \multicolumn{8}{|c|}{ BES } \\
\hline & \multicolumn{4}{|c|}{$\begin{array}{c}\text { Moderate } \\
\mathrm{n}=58\end{array}$} & \multicolumn{4}{|c|}{$\begin{array}{c}\text { Severe } \\
\mathrm{n}=8\end{array}$} \\
\hline & Mean & SD & $r$ & $p$ & Mean & SD & $r$ & $p$ \\
\hline 1. Physical Health & 59.90 & 12.15 & -.113 & 256 & 49.11 & 17.68 & -.774 & .707 \\
\hline 2. Psychological Health & 56.94 & 16.73 & .017 & & 41.67 & 17.39 & -.543 & \\
\hline 3. Social Relationship & 61.11 & 18.92 & .128 & & 55.21 & 22.24 & -.700 & \\
\hline 4. Environment & 60.75 & 16.27 & -.146 & & 51.56 & 9.45 & -.462 & \\
\hline
\end{tabular}

Note: Note: Bold coefficient correlation is significant ( $<<0.05 ; 2$-tailed); $n$ : number of subject; $M$ : mean; SD: standard deviation; WHOQOL-BREF : World Health Organization Quality of Life Scale-Abbreviated form; BES: Binge Eating Scale.

this study. Quality of life showed a correlation with binge eating. When a person feels high life satisfaction then he feels a high level of quality of life and tends to stay away from binge eating. The lower the level of wellbeing, the higher the level of binge eating.

Some weaknesses of this study need to be considered in interpreting the findings, namely that this study is a cross-sectional study with survey data collection based on self-reports, data presented in descriptive form, and correlations only on the total scores of the two measuring instruments. This study had more participants in women and more in one ethnic group, namely Javanese ethnicity, so it cannot be generalized to other sexes or ethnicities.

\section{References}

American Psychiatric Association. (2013). Diagnostic and Statistical manual of Mental Disorders Fifth Edition DSM-5 (5th ed.). Washington: American Psychiatric Association.

Ariwibowo, G. A. (2015). Pendidikan Selera : Perkembangan Budaya Makan Dalam Rumah Tangga Urban Jakarta Pada Periode 1950-An. Patanjala, 7, 311-326. Retrieved from https://media.neliti.com/media/ publications/291822-pendidikan-seleraperkembangan-budaya-ma-5f1e8750.pdf

Cepeda-benito, A., Carmen, M., \& Moreno, S. (2003). Relationship of gender and eating disorder symptoms to reported cravings for food : construct validation of state and trait craving questionnaires in Spanish. Appetite, 40, 47-54. https://doi. org/10.1016/S0195-6663(02)00145-9
Chao, A. M., Grilo, C. M., \& Sinha, R. (2016). Food cravings, binge eating, and eating disorder psychopathology: Exploring the moderating roles of gender and race. Eating Behaviors, 21, 41-47. https://doi. org/10.1016/j.eatbeh.2015.12.007

Deluchi, M., Costa, F. S., Friedman, R., Gonçalves, R., \& Bizarro, L. (2016). Attentional bias to unhealthy food in individuals with severe obesity and binge eating. Appetite, 108, 471-476. https:// doi.org/10.1016/j.appet.2016.11.012

Duarte, C., \& Pinto-Gouveia, J. (2016). Body image flexibility mediates the effect of body image-related victimization experiences and shame on binge eating and weight. Eating Behaviors, 23, 13-18. https://doi. org/10.1016/j.eatbeh.2016.07.005

Duarte, C., \& Pinto-Gouveia, J. (2017). The impact of early shame memories in Binge Eating Disorder: The mediator effect of current body image shame and cognitive fusion. Psychiatry Research, 258(November 2016), 511-517. https:// doi.org/10.1016/j.psychres.2017.08.086

Duarte, C., Pinto-Gouveia, J., \& Ferreira, C. (2015). Expanding binge eating assessment: Validity and screening value of the Binge Eating Scale in women from the general population. Portuguese Foundation for Science and Technology, 18, 41-47. https://doi.org/10.1016/j. eatbeh.2015.03.007

Escrivá-martínez, T., Galiana, L., \& Rodríguezarias, M. (2019). The Binge Eating Scale: Structural Equation Competitive Models, Invariance Measurement Between Sexes, and Relationships With Food Addiction, Impulsivity, Binge Drinking, and Body Mass Index. Frontier in 
Psychology, 10(March), 1-12. https:// doi.org/10.3389/fpsyg.2019.00530

Fichter, M. M., Quadflieg, N., \& Hedlund, S. (2008). Long-Term Course of Binge Eating Disorder and Bulimia Nervosa : Relevance for Nosology and Diagnostic Criteria. International Journal of Eating Disorders, 41, 577-586. https://doi.org/10.1002/ eat.20539

Gan, W. Y., Mohamad, N., \& Law, L. S. (2018). Factors Associated with Binge Eating Behavior among Malaysian Adolescents. Nutrients, 10(66). https:// doi.org/10.3390/nu10010066

Goodwin, K. A., \& Goodwin, C. J. (2017). Research In Psychology Methods and Design (Eighth Edi). Hoboken, USA: John Wiley \& Sons, Inc.

Gormally, J. I. M., Black, S., Daston, S., \& Rardin, D. (1982). The Assessment Of Binge Eating Severity Among Obese Persons. Addictive Behaviors, 7(1), 47-55. https://doi.org/10.1016/03064603(82)90024-7

Grilo, C. M., White, M. A., Gueorguieva, R., Barnes, R. D., \& Masheb, R. M. (2013). Self-help for Binge Eating Disorder in Primary Care: A Randomized Controlled Trial with Ethnically and Racially Diverse Obese Patients. Behav Res Ther, 51(12), 1-18. https://doi.org/10.1016/j. brat.2013.10.002.Self-help

Hudson, J. I., Hiripi, E., Jr., H. G. P., \& Kessler, R. C. (2007). The Prevalence and Correlates of Eating Disorders in the National Comorbidity Survey Replication. Biol Psychiatry, 61(3), 348-358. https:// doi.org/10.1016/j.biopsych.2006.03.040

International Test Commission. (2016). The ITC Guidelines for Translating and Adapting Tests (Second edition), 1-40.

Keel, P. K., Haedt-Matt, A. A., Hildebrandt, B., Bodell, L. P., Wolfe, B. E., \& Jimerson, D. C. (2018). Satiation deficits and binge eating: Probing differences between bulimia nervosa and purging disorder using an ad lib test meal. Appetite, 127, 119-125. https://doi.org/10.1016/j. appet.2018.04.009

Kessler, R. C., Berglund, P. A., Chiu, W. T., Deitz, A. C., Hudson, J. I., Shahly, V., ... Xavier, M. (2013). The prevalence and correlates of binge eating disorder in the WHO World Mental Health Surveys. Biological Psychiatry, 73(9), 904-914. https://doi. org/10.1016/j.biopsych.2012.11.020.The

Kushner, R. F., \& Foster, G. D. (2000). Obesity and Quality of Life. Nutrition, 16(10), 947952. https://doi.org/10.1016/S0899-
9007(00)00404-4

Post, M. W. M. (2014). Definitions of Quality of Life : What Has Happened and How to Move On. Top Spinal Cord Inj Rehabilitation, 20(3), 167-180. https://doi.org/10.1310/ sci2003-167

Purba, F. D., Hunfeld, J. A. M., Iskandarsyah, A., Fitriana, S., Sadarjoen, S. S., Passchier, J., \& Busschbach, J. J. V. (2018). Quality of life of the Indonesian general population : Test-retest reliability and population norms of the EQ-5D-5L and. PLOS ONEONE, May(13), 1-20. https://doi.org/10.1371

Rieger, E., Wilfley, D. E., Stein, R. I., Marino, V., \& Crow, S. J. (2005). Regular Article A Comparison of Quality of Life in Obese Individuals with and without Binge Eating Disorder. International Journal Eating Disorder, 37, 234-240. https://doi. org/10.1002/eat.20101

Skevington, S M, Lotfy, M., \& Connell, K. A. O. (2004). The World Health Organization's WHOQOL-BREF quality of life assessment : Psychometric properties and results of the international field trial A Report from the WHOQOL Group q. Quality of Life Research, 13, 299-310. https://doi.org/10.1023/ B:QURE. 0000018486.91360 .00

Skevington, Suzanne M. (2002). Advancing cross-cultural research on quality of life: Observations drawn from the WHOQOL development. Quality of Life Research, 11(2), 135-144. https://doi. org/Skevington, S. M. (2002). Quality of Life Research, 11(2), 135-144. doi:10.1023/a:1015013312456

Stice, E., Presnell, K., \& Spangler, D. (2002). Risk Factors for Binge Eating Onset in Adolescent Girls : A 2-Year Prospective Investigation. Health Psychology, 21(2), 131-138. https://doi.org/10.1037//02786133.21.2.131

Samiaji, H. M. (2019). Nak, Kalau Makan Harus Dihabiskan!. Retrieve from https:// sahabatkeluarga.kemdikbud.go.id/laman/ index.php? $r=$ tpost $/$ xview\&id $=249900592$

Thurston, I. B., Hardin, R., Kamody, R. C., Herbozo, S., \& Kaufman, C. (2018). The moderating role of resilience on the relationship between perceived stress and binge eating symptoms among young adult women. Eating Behaviors, 29(April 2017), 114-119. https://doi. org/10.1016/j.eatbeh.2018.03.009

WHO. (1996). Introduction, Administration, Scoring And Generic Version of The Assessment. Programme On Mental Health World Health Organization, (December).

WHO. (2012). WHOQOL User Manual. 
Division Of Mental Health And Prevention Of Substance Abuse World Health Organization, WHO/HIS/HS.

Zwaan, M. De, Mitchell, J. E., Howell, L. M., Monson, N., Swan-kremeier, L., Roerig, J.
L., ... Crosby, R. D. (2002). Two Measures of Health-Related Quality of Life in Morbid Obesity. Obesity Research Vol., 10(11), 1143-1151. https://doi.org/10.1038/ oby. 2002.155 